\title{
Pros and Cons for the Laboratory Quality Management System in the Academic Environment ${ }^{+}$
}

\author{
David Milde \\ Department of Analytical Chemistry, Faculty of Science, Palacký University in Olomouc, Olomouc, \\ 17. Listopadu 12, 77146 Olomouc, Czech Republic; david.milde@upol.cz \\ + Presented at the Virtual Eurachem Workshop 2020-“Quality Assurance for Analytical Laboratories in the \\ University Curriculum", 14-15 July 2020; Available online: https://eurachem2020.ro/.
}

Published: 17 September 2020

Keywords: good manufacturing practice; university; inductively coupled plasma mass spectrometry; elemental impurities

Experience with the implementation of a quality management system (QMS) at the research laboratory of a public university in the Czech Republic will be presented in this talk. The close cooperation with a pharma sector has led us to the process of implementation of a QMS in accordance with requirements of a control laboratory working under good manufacturing practice (GMP). This was successfully completed by inspection of the competent authority of the Czech Republic in 2015 and repeatedly re-inspected in 2017 and 2019. The crucial steps in the implementation process and sustainability of the certificates in the laboratory that are mainly focused on research will be presented. Different aspects focusing on documentation, personnel, instrumentation, daily routines in the lab and economic issues will be discussed.

What we have learned from abiding quite strict rules for contract research will be shown on the topic of elemental impurities determination in pharmaceutical products using inductively coupled plasma mass spectrometry. Issues such as metrological traceability of the results, validation of measurement procedures and comparing results with a specification required incorporation, not only when we run analyses for customers but also during the routine research work of every staff member of the control laboratory.

At the end of the lecture, pros and cons from about 7 years of experience with the operation of the control laboratory will be summarized.

Funding: This research was funded by Ministry of Education, Youth and Sports of the Czech Republic (LTV 200008).

Conflicts of Interest: The author declares no conflict of interest.

(C) 2020 by the authors. Licensee MDPI, Basel, Switzerland. This article is an open access article distributed under the terms and conditions of the Creative Commons Attribution (CC BY) license (http://creativecommons.org/licenses/by/4.0/). 